\title{
Expansão das receitas próprias: análise das alternativas dos municípios do COREDE Vale do Rio Pardo - RS
}

\author{
Reisoli Bender Filho \\ Universidade Federal de Santa Maria - Santa Maria - RS - Brasil \\ ORCID: 0000-0002-1019-4414 \\ Mariângela Ravanello \\ Universidade Federal de Santa Maria - Santa Maria - RS - Brasil \\ ORCID: 0000-0001-5484-9702
}

\section{Resumo}

O momento de instabilidade econômica impõe desafios cada vez maiores à gestão dos municípios, interferindo diretamente na arrecadação tributária. A partir deste cenário, estruturou-se o objetivo de analisar alternativas à expansão da arrecadação própria dos municípios do COREDE Vale do Rio Pardo, no período de 2009 à 2016. Metodologicamente, trata-se de estudo descritivo, de cunho quanti-qualitativo, cujo método de abordagem é analítico-comparativo, aplicado à análise dos 23 municípios que foram estratificados em três grupos, conforme faixa populacional: grupo 3, municípios com população inferior a 10.000 habitantes; grupo 2, entre 10.000 e 50.000 habitantes e; grupo 1, maiores de 50.000 habitantes. Os resultados demonstraram que os grupos 2 e 3 possuem atividade econômica pouco expressiva, basicamente rural, inexpressiva participação na arrecadação própria, de 2,52 e 5,35\%, respectivamente, precária estrutura organizacional do setor tributário e quadro singular de profissionais; já no grupo 1, os municípios são mais estruturados economicamente e a arrecadação própria atingiu média de 11,68\%. Ademais, constatou-se que os municípios dos grupos 2 e 3 estão na fase inicial de implementação de ações, porém estão buscando alavancar a arrecadação própria, mesmo que ainda, caso da maioria, não tenham se adequado as exigências normatizadas pelo TCE/RS.

Palavras chave: Finanças municipais. Receitas próprias. FPM.

\section{Expansion of own revenue: analysis of the alternatives of the municipalities of the} COREDE Rio Pardo Valley - RS

\section{Abstract}

The moment of economic instability imposes ever greater challenges to the management of municipalities, directly interfering in the tax collection. Based on this scenario, the objective of analyzing alternatives for the expansion of the own collection of the municipalities of the COREDE Rio Pardo Valley, from 2009 to 2016. Methodologically, it is a descriptive study, of a quanti-qualitative nature, whose approach method is analyticalcomparative, applied to the analysis of the 23 municipalities that were stratified in three 
groups, according to the population range: group 3, municipalities with population less than 10,000 inhabitants; group 2, between 10,000 and 50,000 inhabitants and; group 1, over 50,000 inhabitants. The results showed that groups 2 and 3 have little expressive economic activity, basically rural, meaningless participation in the own collection, of 2.52 and $5.35 \%$, respectively, precarious organizational structure of the tax sector and singular staff; in group 1, the municipalities are more economically structured and their own collection reached an average of $11.68 \%$. In addition, it was found that the municipalities in groups 2 and 3 are in the initial phase of implementing actions, however they are seeking to leverage their own collection, even if, in the majority, the requirements standardized by the TCE/RS have not yet been adequate.

Keywords: Municipal finance. Own revenue. FPM.

\section{Expansión de ingresos propios: análisis de alternativas de los Municipios de COREDE Vale do Rio Pardo - RS}

\section{Resumen}

El momento de inestabilidad económica impone desafíos cada vez mayores a la gestión de los municipios, lo que interfiere directamente en la recaudación de impuestos. Con base en este escenario, el objetivo fue analizar alternativas a la expansión de la colección propia de los municipios de COREDE Vale do Rio Pardo, en el período de 2009 a 2016. Metodológicamente, es un estudio descriptivo, de carácter cuantitativo, cuyo El método de enfoque es analítico-comparativo, aplicado al análisis de los 23 municipios que se estratificaron en tres grupos, de acuerdo con el rango de población: grupo 3, municipios con una población menor de 10,000 habitantes; grupo 2, entre 10,000 y 50,000 habitantes y; grupo 1, más de 50,000 habitantes. Los resultados mostraron que los grupos 2 y 3 tienen poca actividad económica expresiva, básicamente rural, participación sin sentido en la propia colección, de 2.52 y $5.35 \%$, respectivamente, estructura organizativa precaria del sector tributario y personal singular; El grupo 1, a su vez, con una población superior a 50.000 habitantes, los municipios son más estructurados económicamente y la recaudación propia alcanzó la media del 11,68\%. Además, se constató que los municipios de los grupos 2 y 3 están en la fase inicial de implementación de acciones, pero están buscando apalancar la recaudación propia, aunque aún, caso de la mayoría, no se hayan adecuado las exigencias normatizadas por el TCE / RS.

Palabras clave: Finanzas municipales. Recetas propias. FPM.

\section{Introdução}

Nos anos recentes, o Pacto Federativo ${ }^{1}$ tem consolidado a distribuição assimétrica dos tributos, sendo que a União tem mantido, em média, 57\% da receita, os estados $25 \%$ e os municípios $18 \%$ do total dos recursos arrecadados. Essa divisão fundamenta o "Movimento do Bolo", organizado pela Federação das Associações dos Municípios do Rio Grande do Sul, mobilizando-os a questionarem a pequena parcela na divisão da totalidade dos tributos, dado que menos de um quinto dos impostos retorna para esses entes (FAMURS, 2017).

'A autonomia no relacionamento e a definição clara das atribuições de cada ente federado demonstra a necessidade da objetiva distribuição das competências próprias e exclusivas, importando concentrar a atenção nas transferências de encargos administrativos, bem como nos respectivos recursos financeiros para suportarem a execução das atividades para o bem comum (EIDT, LIMA, 2008). 
Por outro lado, a conjuntura econômica adversa, iniciada ainda em 2008, fez o país adotar algumas medidas estabilizadoras, como a desoneração do Imposto sobre Produtos Industrializados (IPI), novas linhas de crédito e aumento nos limites de financiamento das despesas governamentais. Como consequência, a crise dos municípios agravou-se nos últimos anos, sobremaneira após 2014, gerando queda nos repasses constitucionais, com destaque para o Fundo de Participação dos Municípios (FPM), principal receita ao equilíbrio dos orçamentos municipais, o qual representa mais de $70 \%$ das receitas orçamentárias desses entes (FINBRA, 2012) e, para 81\% deles, é a principal fonte de recursos (BREMAEKER, 2011 apud SANTOS, 2008).

Neste cenário, as receitas próprias municipais ganham importância singular na estrutura orçamentária dos municípios. De acordo com Cruz (2008), estas receitas originam-se da cobrança de tributos pagos pela população e tem por base suas propriedades, suas rendas, suas atividades e os benefícios diretos e imediatos que lhes são propiciados pelo Estado ${ }^{2}$.

Considerando o regramento fiscal associado ao crescimento das dificuldades que os municípios possuem em fiscalizar e arrecadar, Teixeira (2002) salienta que é importante que os municípios desenvolvam políticas públicas, ações proativas no sentido de aumentar e otimizar a arrecadação própria, pois a frágil base econômica, ao lado da ineficiência administrativa resulta em orçamentos com recursos próprios na faixa dos $5 \%$ do total das receitas na maioria dos municípios brasileiros.

Situação igualmente é encontrada no Conselho Regional de Desenvolvimento (COREDE) Vale do Rio Pardo, na região central do estado do Rio Grande do Sul. Conforme Petry e Silveira (2017), os 23 municípios que a compõem apresentam elevada heterogeneidade em termos geográficos, socioeconômicos e fiscais. Todavia, o cenário se mostra mais preocupante nos municípios menores, os quais possuem reduzida estrutura urbana, são totalmente dependentes das transferências constitucionais e possuem capacidade tributária própria variando entre 2,51 e 5,35\%. Além disso, as dificuldades financeiras também estão associadas à falta de controle fiscal, restringindo a execução de projetos necessários, diminuindo com isso a qualidade dos serviços prestados.

Entretanto, a continuidade do funcionamento dos serviços públicos básicos, entre eles os prioritários (educação, assistência social e saúde), tem ocorrido a partir da adoção de medidas de contenção, como corte de horas extras e diárias, redução de gastos administrativos, demissão de cargos de confiança e comissionados, além da redução de algumas atividades, como manutenção de estradas (FAMURS, 2015).

Estas condições amplificam o cenário de dependência dos municípios dos recursos de transferências dos demais entes públicos, os quais também têm apresentado sérias dificuldades financeiras, resultando na retração da arrecadação e, consequentemente, dos repasses. Cenário que alinha-se a discussão sobre o equilíbrio fiscal municipal e fundamentam a problemática: Quais as ações que os

2 Ressalta-se que, todo município tem o poder de instituir as alíquotas de impostos bem como aplicar benefícios, isenções e incentivos fiscais, conforme trata o art. 156 da Constituição Federal de 1988, dando aos municípios formas de competir entre si para o desenvolvimento econômico com propostas e legislações de incentivo ao desenvolvimento econômico de sua extensão. 
municípios do COREDE Vale do Rio Pardo estão desenvolvendo e quais as alternativas à expansão das receitas próprias?

Em termos de objetivos, propõe-se analisar a estrutura orçamentária dos municípios do COREDE do Vale do Rio Pardo, no período de 2009 à 2016, discutindo as alternativas a serem implantadas nos setores de arrecadação e tributação, visando melhorias no fluxo das atividades desempenhadas para o fortalecimento da arrecadação própria. A isso soma-se o atual cenário da gestão pública, com problemas econômicos, fiscais, sociais e políticos que têm tornado constantes as manifestações por melhorias na aplicação e na alocação dos recursos públicos.

Nesse contexto, corroborando com Souza (2004), torna-se fundamental aprofundar o conhecimento sobre as finanças públicas municipais dado que os recursos à disposição da esfera local influenciam não só a governança local, mas também o provimento de serviços públicos. Portanto, pretende-se subsidiar essa lacuna sobre receitas próprias municipais, que focaliza, em geral, em alternativas possíveis para que estes entes, que estão em momento singular, ampliem sua capacidade contributiva e, ao mesmo tempo, diminuam o crescente processo de dependência de recursos de transferências. Situação constante à maioria dos municípios brasileiros e característico dos do COREDE Vale do Rio Pardo.

Além desses aspectos, o COREDE, por compor-se de municípios com elevada heterogeneidade (PETRY E SILVEIRA, 2017), possui predominância de municípios de pequeno porte, com população abaixo de 10.000 habitantes, caso de $61 \%$ deles. Ainda, esses municípios possuem base agrícola e estruturas de arrecadação insuficientes. Características que, conforme Martins Filho (2007) e Scur e Platt Neto (2011), confirmam a realidade da maioria dos municípios brasileiros de pequeno porte, de crescente dependência financeira das transferências dos entes federativos superiores.

Condições essas que são complementadas por Santos e Santos (2008) quando enfatizam que, quanto menor o porte demográfico dos municípios, menor é a sua arrecadação tributária, não apenas pelo seu menor quantitativo, mas também pelo fato de que os principais tributos municipais têm sua base de tributação no meio urbano, prevalecendo a característica rural e maior dependência dos repasses de recursos dos demais entes públicos, ficando ainda mais suscetíveis aos impactos econômicos e fiscais em períodos de crise.

Além desta introdução, o trabalho está estruturado em outras quatro seções. Na segunda é detalhado o referencial teórico sobre a estrutura arrecadatória municipal; na terceira é apresentada a metodologia; na sequência, os resultados são discutidos e; por fim, na última seção, delineiam-se as conclusões.

\section{Arrecadação pública: instrumentos legais e alternativas à expansão das receitas municipais}

\subsection{Competência tributária}

As receitas tributárias correspondem ao ingresso de recursos no patrimônio público e se refletem no aumento das disponibilidades, conforme Baio (2013). Corroborando este entendimento, Kohama (2012) denomina como receita pública todo e qualquer recolhimento aos cofres públicos e também, a variação ativa, 
proveniente do direito a receber no momento da ocorrência do fato gerador, quer seja efetuado por meio de numerário ou de outros bens representativos de valores.

$\mathrm{Na}$ interpretação de Jardim (2011), a Lei n 4320, de 17 de março de 1964, que estabeleceu normas de finanças públicas, determina receita como o ingresso de recursos financeiro aos cofres, independente do acréscimo ao patrimônio líquido. Neste sentido, faz-se importante ressaltar as competências tributárias entre os entes da federação, como determina a Constituição Federal de 1988, em seu art. 156.

A competência tributária é a prerrogativa de legislar sobre a matéria tributária em toda sua plenitude, o que supõe a edição de normas direta ou indiretamente relacionadas com o plano do nascimento, existência ou extinção da obrigação tributária. Conforme Jardim (2011), consiste no meio pelo qual o constituinte outorgou às pessoas políticas a faculdade de versar sobre tributação.

Porém, a CF/1988 não criou tributos, apenas estabeleceu as competências de tributação de acordo com o que cada ente pode legislar. O artigo n. 153 assegura que a União pode instituir impostos sobre a importação de produtos estrangeiros, exportação de produtos nacionais ou nacionalizados, renda e proventos de qualquer natureza, produtos industrializados, operações de crédito, câmbio e seguro, ou relativas a títulos ou valores mobiliários, propriedade territorial rural e também grandes fortunas.

Aos Estados e ao Distrito Federal compete instituir impostos sobre transmissão causa mortis e doação, de quaisquer bens ou direitos, operações relativas à circulação de mercadorias e sobre prestação de serviços de transporte interestadual e intermunicipal e de comunicação, ainda que as operações e as prestações se iniciem no exterior, e propriedade de veículos automotores. Já aos Municípios compete instituir impostos sobre propriedade predial e territorial urbana, transmissão "inter vivos", a qualquer título, por ato oneroso, de bens imóveis, por natureza ou acessão física, e de direitos reais sobre imóveis, exceto os de garantia, bem como cessão de direitos à sua aquisição e sob serviços de qualquer natureza.

No que tange aos entes locais, Silva (1996) ressalta que esses enfrentam dificuldades na arrecadação tributária devido a fatores econômicos, administrativos e/ou políticos, os quais geram desequilíbrios nas finanças públicas. Portanto, mesmo com uma estrutura de competências tributárias definida, existe a necessidade de um sistema de transferências intergovernamentais de recursos, com origem nos níveis superiores de governo (União e Estados), voltadas aos níveis inferiores (Municípios).

\subsection{Repartição da receita: recursos de transferências e tributos municipais}

A Constituição Federal de 1988 repartiu as competências tributárias, de modo que cada ente possua sua competência privativa e exclusiva, vedada a bitributação. Além de definida na Constituição Federal, a repartição tributária está estabelecida no Código Tributário e nas Leis Complementares, sendo que para cada tributo partilhado segue uma regra específica.

Também é característico que a maior arrecadação ocorrerá no nível mais amplo e menor nos níveis locais, tornando necessária a transferência de recursos da 
instância central aos governos subnacionais (REZENDE, 2006). A transferência, além de corrigir as diferenças entre atribuições e receitas nos diferentes níveis de governo (ou o desequilíbrio vertical na federação), representa uma oportunidade de atenuar as disparidades regionais. Baiao (2013) salienta, ainda, que o território de um país raramente é homogêneo do ponto de vista econômico e social.

No art. 158, a CF/1988 estabelece que pertencem aos Municípios: o produto da arrecadação do imposto da União sobre renda e proventos de qualquer natureza, $50 \%$ do produto da arrecadação do imposto da União sobre a propriedade territorial rural, $50 \%$ do produto da arrecadação do imposto do Estado sobre a propriedade de veículos automotores e $25 \%$ do produto da arrecadação do imposto do Estado sobre operações relativas à circulação de mercadorias e sobre prestações de serviços de transporte interestadual e intermunicipal e de comunicação (BRASIL, 2013).

Ainda, devido as desigualdades regionais e a grande extensão territorial, as transferências aos governos subnacionais tornam-se ainda mais importantes. Conforme destaca Rezende (2006), um dos desafios do federalismo fiscal tem sido enfrentar a ampliação das disparidades regionais, que concentram as bases tributárias em pontos específicos do território e, consequentemente, afetam a repartição das receitas tributárias entre os entes federativos.

Assim, todas as unidades federativas centralizam, em algum grau, sua arrecadação tributária, apesar da tendência de descentralização verificada nas últimas décadas (ABRÚCIO, 2005). Conforme destaca Prado (2007), na totalidade das economias globais, os governos dos níveis superiores arrecadam mais do que gastam, enquanto os de níveis inferiores gastam mais do que arrecadam, recebendo assim, o nome de brecha vertical, o que explica o fato de todas as federações fazerem uso de transferências verticais.

Neste sistema, as receitas próprias dos municípios são aquelas oriundas da cobrança de tributos no qual o ente da federação tem competência para instituir e arrecadar. É fixada uma alíquota a um fato gerador específico, seja ele por rendas ou pela atividade desenvolvida ou dentre outras formas previstas em lei, aplicada ao contribuinte. As receitas correntes tributárias, conforme Cruz (2008), originam-se da cobrança de tributos pagos pela população e tem por base propriedades, rendas, atividades e benefícios diretos e imediatos que lhes são propiciados pelo Estado.

Por sua vez, ressalta-se que todo município tem o poder de instituir as alíquotas de impostos bem como aplicar benefícios, isenções e incentivos fiscais, conforme trata o art. 156 da Constituição Federal, dando aos municípios formas de competir entre si para o desenvolvimento econômico com propostas e legislações de incentivo ao desenvolvimento econômico de sua extensão.

\subsection{Instrumentos orientadores e alternativas à expansão das receitas tributárias municipais}

A receitas próprias tem recebido tratamento diferenciado por constituir possibilidade de os Municípios aumentarem suas as fontes arrecadatórias. Nesta linha, órgãos consultores e orientadores como a Federação das Associações de Municípios do Rio Grande do Sul (FAMURS), a Confederação Nacional dos Municípios (CMN) como também o Tribunal de Contas do Estado do Rio Grande do 
Sul (TCE/RS) tem divulgado orientações quanto a estrutura, regulamentação e atualização dos instrumentos tributários municipais com o objetivo de possibilitar alternativas à expansão dessas receitas. Orientações essas que foram utilizadas como fonte direta de informações para o embasamento na realização do roteiro da entrevista aplicada aos Municípios do COREDE.

Entre os aspectos destacados por estas instituições à expansão das receitas municipais, destaca-se a Resolução do TCE/RS n. 987/2013 considerando o artigo n. 37, inciso XXII, da Constituição da República, incluído pela Emenda Constitucional n. 42, de 19 de dezembro de 2003, sobre a instituição da administração tributária municipal. Verifica se essa atividade é exercida por servidores de carreira específica, que atuam de forma integrada com as administrações tributárias da União e dos Estados, inclusive com o compartilhamento de cadastros e de informações fiscais e, ainda, se existe estrutura organizacional regulamentada no município com dotação específica no orçamento.

O Instrumento também se refere ao conhecimento do Código Tributário Municipal pelos servidores responsáveis, se promovem medidas de aperfeiçoamento e regulamentação da legislação tributária municipal, bem como adotam providências que buscam a consolidação com lei federal e entendimentos jurisprudenciais, dos tributos ISS, ITBI e IPTU. Além disso, verifica a adequação dos municípios a recente Lei Complementar, de n. 157/2016, que alterou algumas regras sobre o Imposto sobre Serviços (ISS); também como alternativa para incrementar a arrecadação cita a existência do servidor efetivo 'fiscal' e se o mesmo vem realizando, nos últimos mandatos a suas atribuições na adequação e atualização de cadastro imobiliário, planta genérica de valores, das obras em andamento, dos registros dos microempreendedores individuais e demais rotinas ao funcionamento do setor.

Menciona também a Cartilha de Orientação Técnica às Administrações Municipais fornecidas pela FAMURS, o convênio com o Estado do Rio Grande do Sul na realização do Programa de Integração Tributária (PIT), que além de contribuir com Estado na fiscalização da receita de ICMS, proporciona incremento na arrecadação municipal com algumas ações específicas, como o Programa de Educação Fiscal e Incentivo à Emissão de documentos fiscais.

Para finalizar, nos termos previstos na Constituição Federal e, especialmente, na LRF, salienta-se a atuação do Controle Interno como agente verificador, fiscalizar e orientador de mecanismos voltados ao aperfeiçoamento da gestão pública, sobretudo no que concerne à arrecadação municipal.

\section{Metodologia}

\subsection{Delineamento da pesquisa e método de análise}

Os estudos exploratórios permitem ao investigador aumentar sua experiência em torno de determinado problema, devendo manter o tratamento científico presente nos trabalhos de pesquisa, sendo que este tipo de investigação não exime a revisão da literatura, conforme Triviños (1987). Ainda, para a pesquisa ter certo grau de validade científica é necessário uma série de informações sobre o que se deseja pesquisar, com precisa delimitação de estratégias, técnicas e 
procedimentos, métodos e teorias que orientarão a coleta e interpretação dos dados. Assim, permitindo descrever com exatidão os fatos e fenômenos de determinada realidade.

A partir disso, cabe ressaltar que, em razão dos estudos sobre receitas municipais serem pouco debatidos e a literatura ainda escassa, especificamente quanto as alternativas à expansão da arrecadação própria, a estratégia à coleta de informações dar-se-á por meio da participação direta dos agentes envolvidos no fenômeno que se deseja analisar, sendo que o levantamento enquadra-se de forma adequada como tipo de pesquisa.

Porém, o desafio apresentado pela análise qualitativa está na inexistência de fórmulas prontas, sendo assim necessário fornecer um conjunto de dados de entrada, geralmente em forma de texto, não de números. Mais importante, não é possível recorrer a uma fórmula predefinida como na pesquisa quantitativa, devendo desenvolver todo o procedimento substantivo subjacente, tal como classificar, codificar, combinar e recombinar partes do texto (YIN, 2015).

Alinhado a essa definição, foi utilizada a análise de conteúdo, pois consiste em uma técnica que visa a compreensão da comunicação, considerada a mais adequada à interpretação dos dados coletados na pesquisa qualitativa. Para tal, as informações disponíveis pelos órgãos oficiais sobre os municípios foram consideradas unidades que compõem um conjunto de respostas e a confirmação das informações do levantamento obtido por meio das entrevistas.

\section{2 Área de análise, coleta e tratamento dos dados}

A análise compreende os 23 municípios do COREDE Vale do Rio Pardo, localizado na região central do estado do Rio Grande do Sul, no período entre os anos de 2009 e 2016. Este ínterim equivale a duas gestões municipais, facilitando assim as análises comparativa e evolutiva quanto as alternativas à expansão da arrecadação própria municipal.

Para isso, um conjunto de variáveis foram pesquisadas, inicialmente, a partir de legislação específica e junto a publicações dos órgãos consultores (CNM, FAMURS e TCE/RS). Tendo como base de dados secundários os sites: Tribunal de Contas do Estado do Rio Grande do Sul TCE/RS, sistema FINBRA (Finanças Públicas) e Portal da Transparência dos Municípios.

$\mathrm{Na}$ sequência, as alternativas foram examinadas a partir de entrevista semiestruturada realizada junto aos responsáveis pelo setor de arrecadação, preferencialmente o inspetor tributário ou servidor ocupante de cargo efetivo similar, nos municípios do COREDE Vale do Rio Pardo, considerando aqueles com população menor de 50.000 habitantes. Critério que limitou a aplicação das entrevistas em 21 municípios e excluindo outros dois, os quais possuem população superior a 50.000 habitantes e, conforme extrato populacional, definidos como de médio porte.

Essa definição segue a proposta de analisar a estrutura fiscal dos pequenos municípios, os quais apresentam receitas próprias pouco representativas e limitações para sua ampliação. Características essas que alinham-se a discussão empreendida por Martins Filho (2007), Wakulicz e Serpa (2008) e Scur e Platt Neto (2011) quanto aos municípios considerados de pequeno porte, os quais apresentam 
base econômica centralizada em produtos primários e de baixo valor agregado e crescente dependência financeira das transferências dos entes federativos superiores.

Porém, para analisar de forma mais adequada o conjunto total de informações, os municípios foram estratificados em três grupos, conforme faixa populacional: grupo 3, municípios com população inferior a 10.000 habitantes; grupo 2, municípios com população entre 10.000 e 50.000 habitantes e; grupo 1, municípios com população maior de 50.000 habitantes.

\section{Dados secundários}

Os dados secundários atenderam três etapas: na primeira foi realizada uma breve contextualização dos municípios que compõem o COREDE Vale do Rio Pardo por meio de coleta de informações nos site da Fundação de Economia e Estatística (FEE), da Federação da Associação dos Municípios do Rio Grande do Sul e do Portal da Transparência dos Municípios. Na segunda realizou-se pesquisa longitudinal documental levantando informações nos sites oficiais: Tribunal de Contas do Estado TCE/RS, sistema FINBRA (Finanças Públicas) e Portal da Transparência dos Municípios.

$E$, na terceira, foram utilizados os dados quantitativos para realizar o cruzamento das informações, os quais permitiram estabelecer o comportamento, a evolução da arrecadação no período analisado e, principalmente, o comportamento das receitas próprias. Relacionamento que subsidiou o estágio de implementação das ações previstas e indicadas pelo TCE/RS, FAMURS e CNM como alternativas de expansão da arrecadação.

\section{Dados primários}

Os dados primários seguiram a diferentes propósitos. Inicialmente foi realizada entrevista focalizada, aplicada preferencialmente, com os inspetores tributários dos municípios do COREDE Vale do Rio Pardo, com menos de 50.000 habitantes, em um total de 21 municípios. Este tipo de entrevista, do tipo despadronizada, conforme Marconi e Lakatos (2010) segue um roteiro de assuntos relacionados ao problema que pretende estudar. Esta etapa foi realizada entre os meses de agosto e novembro de 2017 , sendo que a entrevista presencial ocorreu em $60 \%$ da amostra e as demais por telefone e por endereço eletrônico.

Neste tipo de entrevista, os entrevistados discorrem acerca de sua compreensão sobre o tema apontado, especialmente quanto às dificuldades na fiscalização das receitas próprias, bem como sobre alternativas específicas que contribuem à expansão (YIN, 2015). Posteriormente, elas foram transcritas, utilizando a análise de conteúdo como técnica à obtenção das informações necessárias de acordo com sua pertinência e adequação aos objetivos propostos.

Quanto ao conteúdo, as entrevistas seguiram a legislação pertinente e correlata às propostas discutidas pela Resolução n. 987/2013, pelos relatórios do Diagnóstico sobre a Estrutura e a Logística da Administração Tributária Municipal, emitidos pelo TCE/RS e pelas notas técnicas emitidas pela CNM e FAMURS. Tais propostas constituem-se em um rol de informações pormenorizadas e atualizadas, embasadas em casos específicos dos municípios. 
Complementando, durante as entrevistas foi realizado debate junto aos responsáveis municipais pela arrecadação, com relação a cada ação proposta e se o município tem realizado ou não, se tem conhecimento de alternativas de incremento da arrecadação do ISS, IPTU e ITBI. Ainda, foi feito o questionamento final, analisando as respostas anteriores em qual fase de implementação das políticas ou esforços para melhorar a arrecadação própria o município se enquadra: fase inicial, intermediária e/ou avançada.

Foram consideradas ações em estágio inicial aquelas que atendem em parte a Resolução TCE n. 987/2013 e realizam pelo menos 25\% das ações propostas, incluindo a figura e atuação do servidor efetivo "fiscal". O estágio intermediário agrega ações de caráter institucional e adequação legal, realizando entre 25 e 50\% das ações propostas, e, por sua vez, o nível avançado atende pelo menos 75\% das ações propostas. De modo amplo, as informações primárias e secundárias possibilitaram a elaboração de relatório demonstrativo das dificuldades enfrentadas pelos municípios na realização da gestão tributária e sugestões de alternativas à expansão das receitas tributárias nos municípios analisados.

\section{Resultados}

\subsection{Caracterização socioeconômica do COREDE Vale do Rio Pardo}

O COREDE Vale do Rio Pardo compreende 23 municípios e conta com população aproximada de 435.000 habitantes. Em termos de atividade econômica e renda, O COREDE apresentou PIB superior a R\$15 milhões e PIB per capita de $\mathrm{R} \$ 22.461,23$ em 2014, conforme FEE (2016).

Entretanto, essa região é bastante heterogênea socioeconomicamente; se, por um lado, o maior município, em termos populacionais e renda, é Santa Cruz do Sul, com mais de 120.000 habitantes e PIB per capita anual superior a R\$60.000,00; por outro, encontram-se os municípios de Herveiras, com contingente populacional de 2.698 habitantes e Boqueirão do Leão com PIBs per capita anual de $\mathrm{R} \$ 13.881,08$ (Tabela 1). Dada essas características, para análises mais detalhadas segue-se com a estratificação dos municípios por grupos (1, 2 e 3), conforme exposto.

Estruturalmente, o grupo 1 está composto por Santa Cruz do Sul e Venâncio Aires, com maior concentração de renda e com população superior a 50.000 habitantes, nos quais se destacam os setores de serviços e indústria, além de contar com importante participação da arrecadação própria. 
Expansão das Receitas Próprias: Análise das alternativas dos Municípios do COREDE Vale Do Rio Pardo - RS

Tabela 1 - Dados socioeconômicos do COREDE Vale do Rio Pardo

\begin{tabular}{|c|c|c|c|}
\hline Municípios & $\begin{array}{c}\text { Habitantes } \\
2015\end{array}$ & PIB (2014) - R\$ mil & $\begin{array}{l}\text { PIB Per capita } \\
(2014)-\mathrm{R} \$ \mathbf{~ m i}\end{array}$ \\
\hline Santa Cruz do Sul & 128.437 & 7.984 .043 & $63.692,48$ \\
\hline Venâncio Aires & 69.052 & 2.810 .741 & $40.430,10$ \\
\hline $\begin{array}{l}\text { Municípios > } 50.000 \text { hab. / } \\
\text { Média Grupo } 1\end{array}$ & 98.745 & $5 \cdot 397 \cdot 392$ & $52.061,29$ \\
\hline Rio Pardo & 38.071 & 744.632 & $19.142,70$ \\
\hline Candelária & 31.083 & 599.666 & $19.093,39$ \\
\hline Vera Cruz & 25.266 & 613.056 & $24.017,85$ \\
\hline Encruzilhada do Sul & 24.625 & 396.616 & $15.464,41$ \\
\hline Sobradinho & 14.789 & 312.550 & $20.970,89$ \\
\hline Arroio do Tigre & 12.699 & 292.431 & $22.025,40$ \\
\hline Vale do Sol & 11.521 & 209.728 & $18.067,58$ \\
\hline $\begin{array}{l}\text { Municípios }>10.000<50.000 \text { hab./ } \\
\text { Média Grupo } 2\end{array}$ & 22.579 & 452.668 & $19.826,03$ \\
\hline Pântano Grande & 9.917 & 258.072 & $25.861,54$ \\
\hline Sinimbu & 9.867 & 178.337 & $17.156,07$ \\
\hline General Câmara & 8.394 & 126.523 & $14.578,05$ \\
\hline Boqueirão do Leão & 7.575 & 109.813 & $13.881,08$ \\
\hline Segredo & 6.785 & 110.478 & $14 \cdot 998,41$ \\
\hline Passo do Sobrado & 6.167 & 140.021 & $22.085,33$ \\
\hline Passa Sete & 4.874 & 84.391 & $15.464,66$ \\
\hline Mato Leitão & $4 \cdot 514$ & 136.373 & $32.774,13$ \\
\hline Ibarama & 4.219 & 70.384 & $15 \cdot 581,96$ \\
\hline Tunas & 4.139 & 65.984 & $14.419,49$ \\
\hline Estrela Velha & 3.526 & 121.599 & $32.487,14$ \\
\hline Vale Verde & 3.305 & 70.676 & $20.665,43$ \\
\hline Lagoa Bonita do Sul & 2.735 & 49.617 & $17.657,43$ \\
\hline Herveiras & 2.698 & 49.244 & $16.092,83$ \\
\hline $\begin{array}{l}\text { Municípios < } 10.000 \text { hab./ } \\
\text { Média Grupo } 3\end{array}$ & 5.623 & 112.251 & $19 \cdot 550,25$ \\
\hline
\end{tabular}

Dados: Adaptado dos dados FEE, 2015.

No grupo 2 encontram-se os municípios com população entre $10.000 \mathrm{e}$ 50.000 habitantes, os quais representam cerca de 30\% do total de municípios do COREDE, sendo eles: Rio Pardo, Candelária, Vera Cruz, Encruzilhada do Sul, Sobradinho, Arroio do Tigre e Vale do Sol. Esses municípios tem como característica variadas fontes arrecadatórias, crescimento da arrecadação própria, no entanto, dependentes do repasse de transferências constitucionais.

E no grupo 3, encontram-se os municípios com população inferior a 10.000 habitantes, os quais somam 14 municípios e correspondem a 61\% do COREDE Vale do Rio Pardo. Esses municípios se caracterizam por apresentar significativa concentração na atividade rural e os menores níveis de renda, como também as receitas próprias representam uma fonte pequena na arrecadação total. Além disso, o setor público (prefeitura) é o maior empregador de trabalhadores.

\subsection{Estrutura orçamentária dos municípios do COREDE do Vale do Rio Pardo}

A distribuição desigual das receitas tributárias entre os entes públicos tem ampliado o debate sobre os limites do modelo federativo, sobremaneira para os municípios, dado que essa estrutura induz esses entes públicos à posição, no 
âmbito da federação, de entidade político-administrativa, de terceiro grau, conforme Eidt e de Lima (2008). Além disso, os municípios tem se tornado cada vez mais vulneráveis a conjuntura econômica decorrente de sua dependência de recursos recebidos por meio de transferências dos demais entes.

Considerando o COREDE Vale do Rio Pardo, a arrecadação dos pequenos municípios (grupo 3), nos anos de 2009 a 2016, apresentou grandes oscilações, variando entre crescimento de até $40 \%$ de um lado e, de outro lado, decréscimo de mais de $10 \%$. Deduz-se daí uma conjuntura de instabilidade financeira e necessidade de esforço gerencial para ajustar os orçamentos e manter o cumprimento de metas de resultados entre receitas e despesas, conforme art. $4^{\circ} \S 1^{\circ}$ da Lei de Responsabilidade Fiscal.

Em termos de evolução da arrecadação total, foram registrados, nos anos de 2010 e 2014 os maiores crescimentos, motivados principalmente por receitas de capital de emendas parlamentares, visto que foram anos eleitorais nas esferas nacional e estadual. Todavia, nos anos de 2013 e 2015, ocorreu processo inverso, com decréscimo da arrecadação total em alguns municípios de pequeno porte, de acordo com o TCE/RS (2017) e Portal da Transparência Municipal (2017) (Figura 1).

Figura 1 - Evolução da arrecadação total dos municípios do grupo 3, entre 2009 e 2016, em \%.

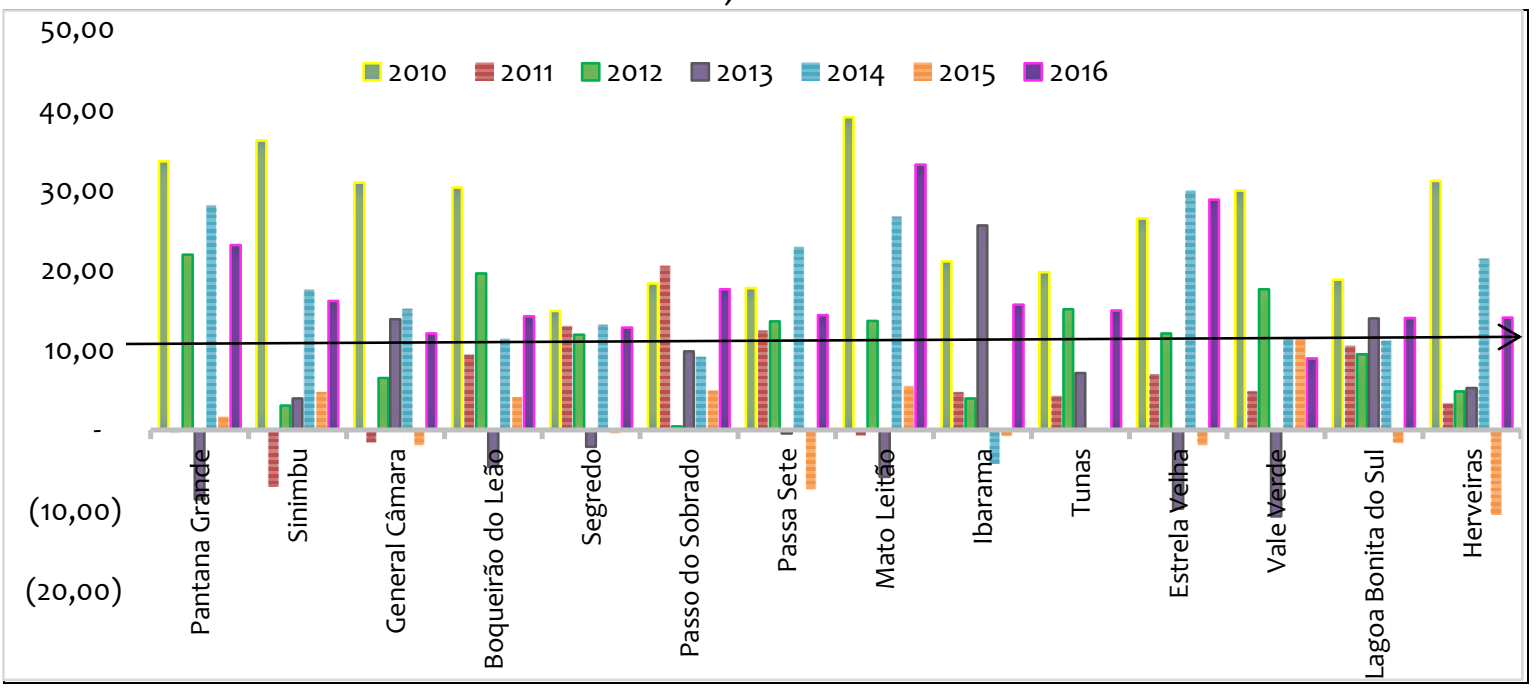

Fonte: Elaborada pelos autores, 2017.

Detalhando, observa-se crescimento médio de aproximadamente $11 \%$ das receitas tributárias, sendo que os maiores aumentos ocorreram em Mato Leitão, Sinimbu e Pântano Grande, respectivamente, nos anos de 2010, 2014 e 2016. De igual forma ocorreu nos demais municípios, com o crescimento direcionado para obras de construção e investimentos, não significando mais recursos para os municípios investirem em despesas correntes com a manutenção da máquina pública e de programas já criados.

Considerando os municípios do grupo 2, observam-se aumentos significativos em todos os anos, principalmente entre 2010 e 2014, com médias de $27 \%$ e $20 \%$ (Figura 2). Entre os determinantes estão os recursos de transferências e as emendas parlamentares entre outros não previstos nos orçamentos iniciais. Citamse os casos de Vale do Sol, cuja arrecadação cresceu 56,11\% em 2010, sendo $20 \%$ 
deste acréscimo apenas com o recurso transferências de convênio dos estados destinadas aos Programas de Infraestrutura em Transporte.

Complementando, quanto ao grupo 1, o qual compõem-se dos dois municípios mais populosos do COREDE (apresentados a direita da Figura 2), verificase evolução arrecadatória em todo o período, com menores percentuais verificados em 2013, 2015 e 2016. Igualmente aos demais, ambos os municípios receberam verbas parlamentares, com repasses distintos em anos eleitorais, no entanto possuem uma consistente base arrecadatória, com destaque para o ICMS, transferências constitucionais (vinculadas a faixa populacional e cidadão atendido áreas de educação e saúde), e também das receitas próprias; aspectos que mais condicionaram a crescimento da arrecadação.

Figura 2 - Evolução da arrecadação dos municípios dos grupos 2 e 1, entre 2009 e 2016, em \%.

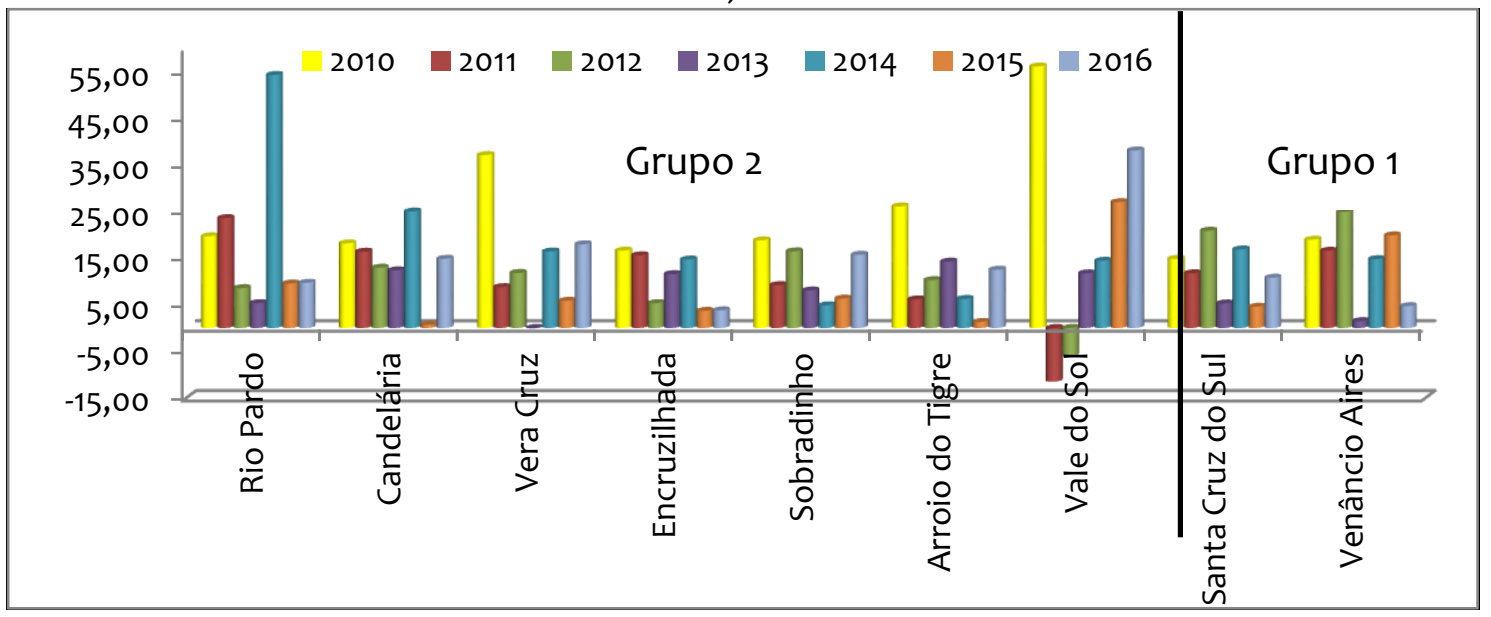

Fonte: Elaborada pelos autores, 2017

\subsection{Análise da arrecadação própria}

Os municípios são os responsáveis pela execução das ações e atendimento das demandas sociais, todavia, é justamente neles que os recursos são primeiramente contingenciados. Os últimos anos, sobremaneira, o biênio 2015/2016, serão lembrados como um dos períodos mais difíceis enfrentados pelo país em sua história recente, com encolhimento da atividade econômica, retração do PIB e aumento da inflação, além da profunda crise política e enfraquecimento institucional.

Neste cenário, os municípios realizaram poucos investimentos, enquadrando-se, em sua grande maioria, nos conceitos "D" - Gestão crítica para receita própria e " $C$ " para investimento - Gestão em dificuldades, demonstrando assim a necessidade de, em curto prazo, melhorar a gestão das receitas próprias, conforme Indicadores de Gestão Fiscal do Sistema Firjan (2017). A partir desse contexto, estruturar as receitas próprias se torna tarefa importante à gestão orçamentária.

Seguindo essa proposta, discute-se a evolução das receitas próprias dos municípios do COREDE Vale do Rio Pardo (IPTU, ISSI e ITBI), no período de 2009 a 2016. De forma geral, observaram-se características similares aos municípios com população agrupada por número de habitantes. Resultados que corroboram o 
exposto por Brito e Dias (2015), quando discutem que os fatores que explicam o comportamento da arrecadação própria estão relacionados à localização dos municípios. Complementando, Santos et al. (2008), ressaltam que, a heterogeneidade dos municípios brasileiros sugere que a estimativa do potencial de receita estará mais livre de vieses de características não-observáveis se a estimativa se der por faixa populacional.

Analisando a estrutura das receitas próprias, para os municípios com população inferior a 10.0000 habitantes (grupo 3), a representatividade média (soma do ISS, ITBI e IPTU) variou entre 0,84\% (Lagoa Bonita do Sul) e 5,48\% (Pântano Grande) da receita total arrecadada no período (Figura 3). Da mesma forma, a participação de cada um dos tributos no montante da arrecadação tributária apresentou grande oscilação no período, sendo que o ISS representou a principal fonte de arrecadação própria para 60\% dos municípios.

Figura 3 - Participação da receita própria dos municípios do grupo 3, no período de 2009 a 2016 , em \%

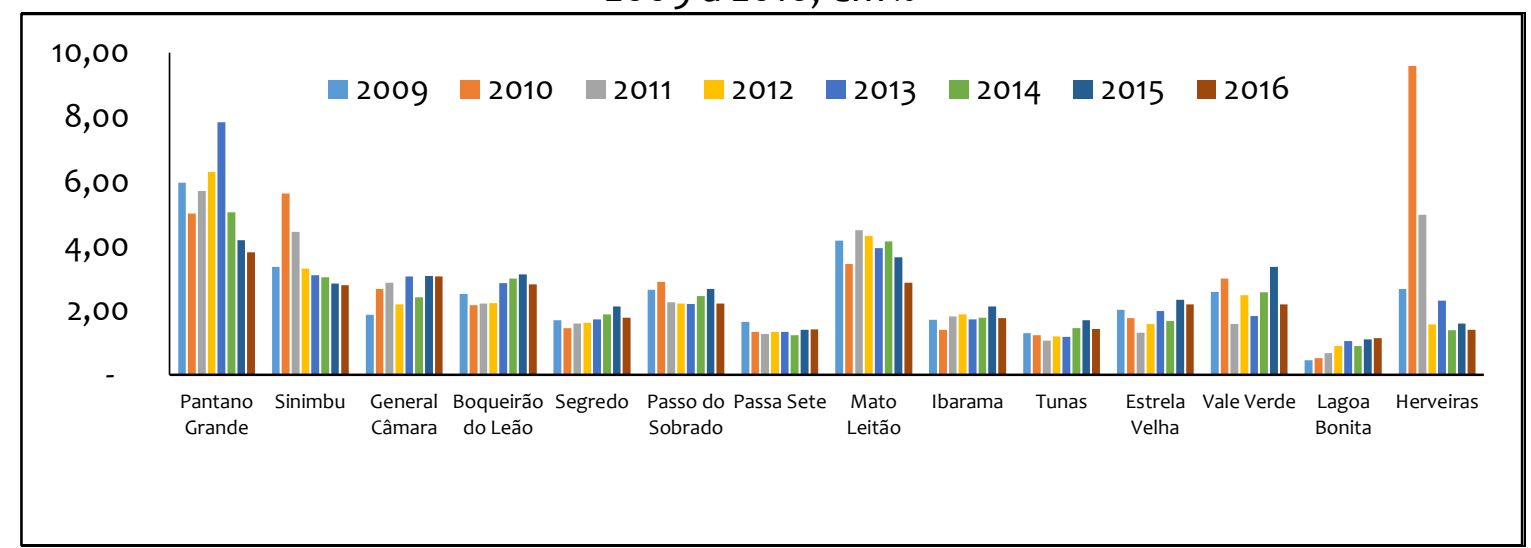

Fonte: Organizada pela autora, 2017.

As maiores médias de participação na arrecadação própria foram encontradas em Pântano Grande, Sinimbu e Mato Leitão, municípios que possuem maior área urbana e maior concentração de empresas (GUIA SOCIOECONÔMICO, 2017). Além disso, os dois primeiros são os mais populosos do grupo 3. Por outro lado, as menores participações foram encontradas nos menores municípios em número de habitantes, caso de Lagoa Bonita do Sul e de Herveiras, os quais possuem apenas empresas de comercialização de produtos, como mercados, farmácias e agropecuárias.

Ainda, observa-se um crescimento variado nos municípios e nas receitas tributárias próprias, com acréscimos principalmente no ano de 2010, caso dos municípios de Sinimbu (128\%), General Câmara (87\%), Passo do Sobrado (29\%), Vale Verde (51\%) e Herveiras (370\%). Por outro lado, os decréscimos foram observados, sobretudo em 2011, em Sinimbu (-26,63\%), Estrela Velha (-20,78\%), Vale Verde ($44,86 \%)$ e Herveiras (-51,60\%).

Por sua vez, o ano de 2010 refletiu situação diferenciada para os municípios de Sinimbu, General Câmara, Passo do Sobrado, Vale Verde e, principalmente, Herveiras, com um significativo crescimento na arrecadação do ISS que mais que dobrou, ocasionado pelos serviços de engenharia, especificamente, serviços de 
empreitada decorrentes da construção da Rodovia Estadual RST 153, que liga os referidos municípios.

Já a arrecadação do IPTU foi a que demonstrou apesentou maior expansão para todos os municípios. Para os inspetores tributários, o acréscimo da arrecadação se deveu a elevação do número de imóveis edificados por meio de programas sociais de habitação do Governo Federal, como também ao crescimento de empreendimentos imobiliários. Ademais, resultaram dos aprimoramentos dos setores e sistemas informatizados e do recadastramento imobiliário, implantado por diversos municípios, caso de Tunas, Lagoa Bonita do Sul e Passa Sete, em 2011 e 2012.

Resultados positivos em termos arrecadatórios também foram encontrados nos municípios de Ibarama, Mato Leitão e Estrela Velha, resultantes da implementação de ações de atualização da planta genérica de valores do IPTU. Por fim, em termos de participação média, encontra-se o ITBI, cuja média no período para os municípios do grupo 3 , foi de $26,87 \%$, com máxima representatividade de 70,14\% no município de Estrela Velha, em 2009, e mínima de 1,25\% em Herveiras, em 2010.

Para aos municípios do grupo 2, constata-se uma estrutura urbana mais ampla, com maior concentração de imóveis e prestação de serviços. Ademais, apresentam equipes com maior número de servidores e com maior capacidade de fiscalização. Condições que possibilitaram a obtenção de uma participação média da receita própria de 5,25\%, praticamente o dobro da média do grupo 3, com variação média entre 3,49\% (Arroio do Tigre) e 6,98\% (Encruzilhada do Sul), conforme figura 4 .

Figura 4 - Participação da receita tributária próprias dos municípios do grupo 2, no período de 2009 a 2016, em \%

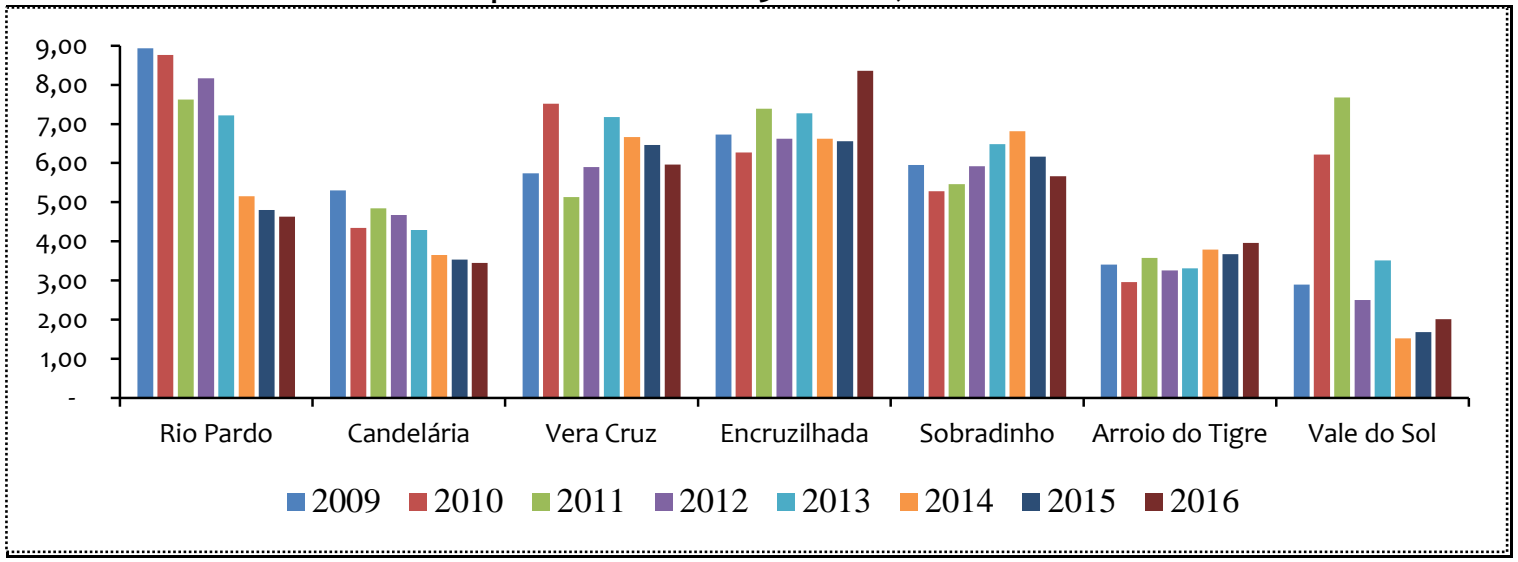

Fonte: Elaborada pelos autores, 2017.

Para esses municípios, o tributo com a maior representatividade foi o ISS, igualmente ao grupo 3, com a média de $47,26 \%$ da receita municipal (Figura 5). A máxima representatividade foi de 90,99\%, obtida por Vale do Sol, em 2010, enquanto que a mínima foi de 16,32\%, encontrada em Vera Cruz, no ano de 2014. Os maiores percentuais de participação deste tributo foram encontrados nos municípios de Vera Cruz e Vale do Sol, nos anos de 2010 e 2011, período em que realizava-se a construção da Rodovia Estadual RST 153, elevando a participação 
tributária na média geral dos recursos arrecadados e reduzindo a participação relativa dos demais tributos.

O IPTU representou a segunda maior fonte de arrecadação tributária com média de 31,90\% no período, com a máxima representatividade de 49,07\% no município de Sobradinho, no ano de 2010, e mínima de 5,77\% encontrada em Vale do Sol, em 2011. Porém, ressalta-se que, para os municípios de Arroio do Tigre e Sobradinho, o IPTU é o tributo de maior representatividade de receita própria.

A estrutura arrecadatória compõe-se ainda está o ITBI, cuja média no período foi de 20,84\%; sendo a máxima representatividade de $48,74 \%$ no município de Encruzilhada do Sul, no ano de 2015, e a mínima de 10,95\%, em Sobradinho, em 2010.

Figura 5 - Representatividade média dos tributos municipais por grupo de análise

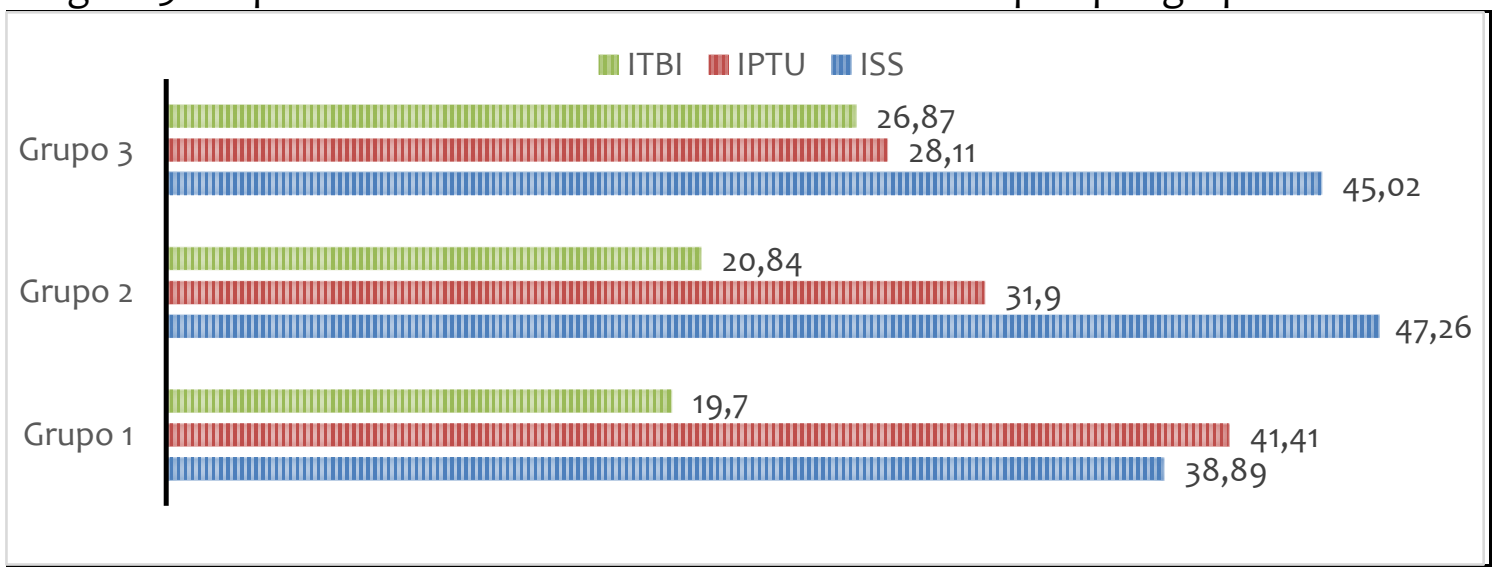

Fonte: Elaborada pelos autores, 2017.

Em relação às receitas próprias, foram realizadas políticas destinadas a melhorar o desempenho tributário, caso do recadastramento imobiliário, da atualização da planta genérica de valores, do aumento do número de fiscais, entre outras ações. Entretanto, verifica-se reduzido crescimento, sendo os acréscimos mais expressivos obtidos pelos municípios de Vera Cruz e Vale do Sol, no ano de 2010.

Outro fator relevante às receitas próprias nos anos recentes foi o cenário de crise econômica que se instalou a partir de 2008 ocasionando redução da arrecadação própria nos anos seguintes (2010, 2012, 2014 e 2015), sobretudo nos municípios de Arroio do Tigre, Sobradinho, Rio Pardo, Candelária, Encruzilhada do Sul, Vera Cruz e Vale do Sol. Esses dois últimos foram os que registraram as maiores quedas na arrecadação do imposto sobre serviço (2011, 2012 e 2014), explicadas pelo incremento arrecadatório atípico dos anos anteriores, motivadas pelas grandes obras e construções nestes munícipios.

Complementando a análise, considerando as receitas próprias e a composição tributária do grupo 1 , os quais tem o IPTU como o tributo mais representativo, com a máxima participação de 56\% para o município de Venâncio Aires, e a média deste grupo em 41,41\%. (Figura 5). Resultados diferentes do que foi apresentado por Brito e Dias (2015) para o município de Parnaíba/PI, com população superior a 140.000 habitantes, os quais apresentaram o ISS como tributo mais representativo, correspondendo à média de $57,48 \%$ da receita tributária, enquanto que a tributação própria representou, em média, 4,29\%. 
Logo, evidencia-se que a estrutura é distinta da dos demais municípios, pois, além da população, esses municípios possuem variada e consistente capacidade industrial e empresarial (baseadas nos setores fumageiro, erva mate, metalúrgico, moveleiro, alimentício, plástico e borracha, vestuário e calçadista), estrutura que se reflete diretamente na arrecadação do ISS e do IPTU, como também na arrecadação do ICMS. A partir de tais definições, no grupo 1, com maior concentração de renda e com população superior a 50.000 habitantes, se destacam os setores de serviços e indústria, representando grande participação de arrecadação própria.

Todavia, quanto à evolução das receitas próprias, verifica-se diferenciação entre os dois municípios. Enquanto que Santa Cruz do Sul mantém constante evolução de seus tributos, Venâncio Aires apresentou expansão até 2014, com ocorrências isoladas que resultaram em oscilações no volume arrecadado. Neste ano em específico, ressalta-se o incremento na arrecadação de IPTU de mais de $100 \%$, reflexo da atualização da planta genérica de valores realizada no ano anterior. Por outro lado, em 2016, o mesmo tributo sofreu queda brusca, quando o legislativo municipal não aprovou o projeto de lei que autorizava a antecipação em cota única do tributo no mês de dezembro.

As evidências possibilitam definir características distintas para os três grupos (3, 2 e 1) quanto a estrutura arrecadatória. Os municípios mais populosos apresentaram média da arrecadação própria de 11,68\%, figura 6, o dobro do grupo 2, que teve média de 5,35\% e quatro vezes maior que os municípios do grupo 3, cuja participação foi de 2,51\%. Quanto à representatividade dos tributos próprios, destaca-se o ISS para os grupos 2 e 3, enquanto que para o grupo 1 o IPTU representou o tributo mais representativo no período, com máxima participação de 56\% no ano de 2015.

Esse cenário de diferenciação na estrutura da arrecadação própria nos municípios do COREDE Vale do Rio Pardo alinha-se a discussão exposta por Santos (2008), como sendo resultado do baixo poder de arrecadação de seus tributos e da predominância da atividade rural dos pequenos municípios. Também, Santos et al. (2008) destacam que a desigualdade da estrutura tributária entre os municípios, de acordo com o tamanho populacional, reforça a necessidade de realizar estimativas de impacto por faixa populacional.

Figura 6 - Participação da receita própria pelos municípios do grupo 1, no período entre 2009 e 2016 , em \%

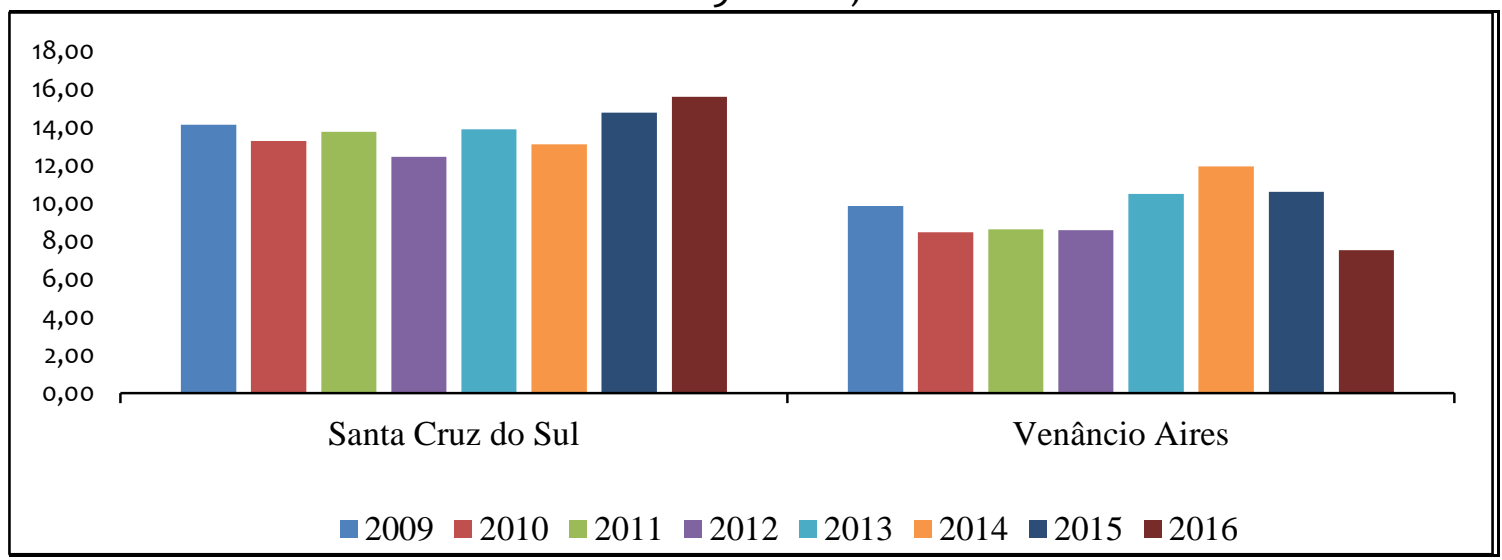

Fonte: Elaborada pelos autores, 2017. 
Santos e Santos (2008) complementam, enfatizando que, primeiro, quanto menor a população dos municípios, menor é sua capacidade de consumo e, consequentemente, menor é sua participação na distribuição do ICMS estadual; segundo, quanto menor o porte demográfico dos municípios, menor é a sua arrecadação tributária, não apenas pelo seu menor quantitativo, mas também pelo fato de que os principais tributos municipais (ISS e IPTU) terem sua base de tributação no meio urbano.

\subsection{Receitas próprias: ações, dificuldades e limitações}

Nesta etapa complementar caracterizou-se a estrutura organizacional dos 21 municípios dos grupos 3 e 2 que apresentaram capacidade arrecadatória própria inferior a 5\%, as alternativas propostas à expansão das receitas, as dificuldades dos setores de fiscalização e arrecadação e a fase de implementação das alternativas à expansão da arrecadação própria.

As informações foram analisadas a partir das entrevistas realizadas com os inspetores tributários, fiscais e secretários municipais, sendo 15 delas executadas presencialmente e as seis restantes por telefone, tendo em vista a disponibilidade dos entrevistados.

Conforme Resolução do TCE/RS n. 987/2013, quanto menor o município, menor a estrutura organizacional e, consequentemente, menor a capacidade de realizar as ações propostas que visam à ampliação da arrecadação própria. Para tanto, os municípios destacam que possuem poucos servidores para atuarem na fiscalização, que priorizam o lançamento e a cobrança e nem sempre conseguem operar nas atribuições inerentes ao cargo. Ambos os grupos não possuem estrutura organizacional distinta com dotação específica à área tributária e fazendária.

Sobre esse aspecto, por um lado, os municípios do grupo 3 destacam que é inviável manter servidor na fiscalização in loco, pois não possuem demanda e, por outro, os municípios do grupo 2, com exceção de Rio Pardo, implementaram a nota fiscal eletrônica como alternativa ao controle e a fiscalização da arrecadação do ISS. Porém, os municípios do grupo 3 estão direcionando ações à implementação desta ferramenta, sendo que até o período analisado somente Vale do Sol a implementou.

Em relação à cobrança dos serviços de construção civil, prevista nos subitens 7.02 e 7.05, da Lista Anexa à Lei Complementar n. 116/2003, tendo em vista 0 entendimento jurisprudencial (STJ e STF) que indica afastar da base de cálculo os valores dos materiais, verificou-se que a maioria dos municípios do grupo 2 (cerca de $70 \%$ ) e do grupo 3 não assentou as alíquotas em seus códigos, cobrando conforme discriminação em documentos fiscais dos serviços prestados pela alíquota anterior. Logo, a base de cálculo permaneceu inalterada na maioria dos municípios, com exceção de Passo do Sobrado, Pântano Grande e Vale do Sol, sendo que esse último apresenta a maior alíquota, de $5 \%$.

Sobre o IPTU, cuja cobrança é calculada em função do valor venal do imóvel, constatou-se que $57 \%$ dos municípios do grupo 3 realizou a atualização da planta genérica de valores ao menos uma vez no período. Nesse grupo, encontram-se ainda Vale Verde e Mato Leitão que realizam a atualização a cada quatro anos, conforme estabelecido em legislação municipal. Por sua vez, no grupo 2, nos oito anos estudados, unicamente Sobradinho e Vale do Sol realização a atualização. 
Considerando que a arrecadação do IPTU representa cerca de $30 \%$ da receita própria desses municípios, a não atualização implica em redução (ou alguma renúncia) de receita. Situação essa destacada por Anselmo (2013), caso a planta não seja refeita e atualizada, os valores do imposto podem ficar desatualizados em relação aos de mercado, desconsiderando a valorização imobiliária e, distorcidos.

Já em relação a fiscalização do IPTU, inclusive ITBI e ISS, foi constatado que $57 \%$ dos municípios do grupo 2 possuem fiscais que atuam diretamente nas ruas, verificando a regularidade das obras de construções e/ou ampliações, registros e alvarás, processo esse que vem ocorrendo nos últimos quatro anos. De outro lado, a grande maioria dos municípios realiza a vistoria por demanda, de acordo com as solicitações recebidas.

Considerando os municípios do grupo 3, apenas Sinimbu apresentou disponibilidade de fiscal de obras à atuação frequente na vistoria in loco. Foi ressaltado por alguns entrevistados que não há demanda para os fiscais estarem diariamente nas ruas, enquanto outros entrevistados evidenciaram que não é uma prática bem vista pelos gestores, que preferem os fiscais atuando nas repartições internas do setor.

À alternativa proposta "Recadastramento Imobiliário", 43\% dos municípios realizaram por meio de terceirização a atualização com vistorias in loco. Outra medida discutida em relação à ampliação da arrecadação se refere ao convênio à municipalização da fiscalização e da cobrança de ITR junto à Secretaria da Receita Federal, pactuação que 43\% dos municípios, dos grupos 2 e 3, realizou. Obviamente que, tanto o recadastramento imobiliário como a descentralização do ITR passa pela análise da sua viabilidade diante do perfil de cada município, mas também depende diretamente da disposição e interesse político do gestor em fiscalizar com maior rigor, promovendo maior equidade tributária. Assim sendo, este é um dos grandes desafios do gestor local, que possui a oportunidade de agir unilateralmente com respaldo da União (CAMPOS E JUNIOR, 2015).

Além do convênio com a União, uma alternativa aos municípios consiste no convênio com o estado para buscar melhorias na arrecadação do ICMS, caso do Programa de Integração Tributária (PIT), instituído pela Lei Complementar n. 63, de 11, de janeiro de 1990, e alterações e decretos posteriores. Dentro desse programa, há várias ações que produzem pontuação para o município, o que proporciona um retorno financeiro direto no ICMS e indireto nas receitas próprias.

Conforme dados da Secretaria Estadual da Fazenda (2017), foi verificado o esforço dos municípios em desenvolver as ações do PIT, de acordo com a pontuação atingida no ano de 2015, que reflete na arrecadação do ano de 2017. Destacam-se Boqueirão do Leão, Encruzilhada do Sul, Mato Leitão e Vera Cruz, que trabalham a Educação Fiscal em seus municípios. Já Arroio do Tigre, Ibarama, Segredo e Sobradinho, mesmo não desenvolvendo Educação Fiscal, possuem um importante retorno das demais ações do PIT, além da digitação das notas do Sitagro, a qual é pontuada por todos, desenvolvem a Turma Volante e a Campanha de Arrecadação municipal. Além do acréscimo na arrecadação, o Programa de Educação Fiscal, amplamente discutido por Junior et al. (2019), transcende as questões de políticas tributárias, estimulando o cidadão a participar ativamente, de forma ética e solidária, na consecução das políticas públicas, contribuindo à promoção do bem comum. 
Os procedimentos legais que compõem as etapas de gestão fiscal vão desde o lançamento tributário até a fiscalização, passando pela cobrança administrativa e a execução fiscal. Cada uma dessas etapas possui características específicas que precisam ser analisadas, aprimoradas e integradas à eficácia da arrecadação dos créditos. Sobre isso, Rocha (2017) destaca que, ocorrendo algum vício ou erro, tal problema inviabilizará a correta recuperação e arrecadação do crédito. Assim, corroborando com as informações obtidas junto aos setores fiscais e tributários, a mais importante providência para uma melhor gestão tributária consiste na otimização das informações por intermédio de um cadastro fiscal completo e continuamente atualizado.

Nesta linha, conforme inspetor tributário de Sobradinho, "as maiores dificuldades encontradas na arrecadação estão na falta de visão técnica por parte dos gestores públicos acerca da aplicação correta da legislação tributária, situação que visa incrementar a arrecadação própria que voltará em forma de benefício, em obras e investimentos para os contribuintes, pois o sucesso da gestão não se mede pela arrecadação, mas pela forma como os valores arrecadados são aplicados". Argumento discutido por Anselmo (2013) ao salientar que, se deve buscar o equilíbrio entre o montante de tributos que a população paga e o que a administração devolve na forma de serviços; para tanto, se torna essencial conhecer a realidade socioeconômica local para possibilitar que esses tributos sejam arrecadados coerentemente e distribuídos de maneira justa.

Este mesmo entendimento foi exposto pelos servidores de Vera Cruz, os quais destacaram a seriedade no fortalecimento do setor de tributação, com gestores preparados e conscientes da importância das ações desenvolvidas. Assim, mesmo com a implementação da nota de serviço eletrônica, é difícil mudar a cultura de emissão de notas fiscais, quando não obrigatória, nem mesmo a população tem o hábito de solicitar. Ademais, citam que o progresso do Programa Educação Fiscal, desenvolvido nas escolas, está propiciando uma nova visão aos pequenos cidadãos e vem contribuindo para quebrar esta cultura tão enraizada nos munícipes.

Também foi enfatizada a criação de muitos programas e incentivos, como os MEls que favorecem as empresas a sair da informalidade, porém reduz a participação dessas no pagamento de impostos, induzindo-as a sonegação emitindo eventualmente a nota fiscal. Situação que os inspetores de Passa Sete, Ibarama e Vale Verde mencionaram como uma dificuldade em seus municípios. Além desses, o servidor de General Câmara, ressaltou ainda que nos municípios de pequeno porte, as pessoas se conhecem e muitas técnicas de cobrança, fiscalização e investigação não são bem aceitas, tanto pela população como pelos gestores, incluindo-se o aspecto político que dificulta as boas e corretas práticas gestão pública.

Afora essas dificuldades, é unanime, entre os gestores tributários, a percepção de que a crise financeira, econômica e fiscal iniciada em 2008 contribuiu para o enfraquecimento da arrecadação das receitas públicas, pois a isenção do IPI impactou diretamente na arrecadação do FPM, principal transferência dos municípios, refletindo no desaquecimento da atividade econômica, na redução do consumo e no aumento da inadimplência. Também, o programa de Educação Fiscal é visto como uma importante ferramenta, além de proporcionar incremento na receita modifica a visão dos cidadãos sobre o sistema de arrecadação e gestão municipal. 
Finalizando, as dificuldades expostas pelos agentes tributários associadas ao arcabouço teórico-legal que consistiram nos aspectos utilizados à formulação da Tabela 2, que apresenta uma síntese das limitações dos municípios dos grupos 2 e 3 quanto à expansão da arrecadação própria.

De forma geral, verifica-se que a maior dificuldade enfrentada por ambos os grupos está na carência de profissionais técnicos capacitados, o que consequentemente acarreta na precária organização do setor de arrecadação e fiscalização. Esta dificuldade foi mais percebida pelo grupo 2, que possui demanda superior à dos municípios menos populosos quanto aos lançamentos, ajustes e atualizações de cadastros, principalmente imobiliários e de empresas, bem como fiscalização e cobrança.

Por outro lado, a última alternativa proposta "Desinteresse dos gestores por não representar uma ação política que some votos" foi anotada por $64 \%$ do grupo 3 , correspondente a nove municípios. Isso evidencia que, quanto menor a população maior a influência política e despreparo dos gestores. Sobre esse aspecto, Lindblom (1981) citado por Kleba, Zampirom e Comerlatto (2015) enfatiza que os administradores precisam dialogar com outros setores, não apenas porque eles não têm o poder exclusivo de decidir, mas também porque podem dessa forma potencializar os recursos, entrando em ajuste com outros executantes e priorizando a implementação de acordos com os recursos material e de pessoal disponíveis.

Observa-se também o elevado percentual de municípios que se ressentem da falta de políticas públicas à valorização do setor de tributação e proposição de ações para ampliar a arrecadação própria a fim de se ter uma gestão financeira eficiente refletindo em melhorias econômicas e sociais.

Tabela 2 - Dificuldades levantadas e enquadramento dos municípios

\begin{tabular}{l|c|c}
\hline \multicolumn{1}{c|}{ Dificuldades levantadas pelo autor } & Grupo 2 & Grupo 3 \\
\hline $\begin{array}{l}\text { a) organização do setor de arrecadação e fiscalização, possuindo } \\
\text { rotinas de procedimentos internos deficientes que precisam ser } \\
\text { ajustadas para que os responsáveis façam a adequado registro, } \\
\text { controle e fiscalização }\end{array}$ & $71 \%$ & $30 \%$ \\
\hline b) a precariedade dos sistemas informatizados & $0 \%$ & $7 \%$ \\
\hline c) a carência de profissionais técnicos e capacitados & $71 \%$ & $64 \%$ \\
\hline $\begin{array}{l}\text { d) a falta de designação de atribuições aos servidores } \\
\text { responsáveis, conforme Resolução TCE/RS n. 987/2013 e } \\
\text { respectiva cobrança pelos seus superiores }\end{array}$ & $57 \%$ & $43 \%$ \\
\hline e) falta de políticas públicas específicas para arrecadação & $30 \%$ & $64 \%$ \\
\hline $\begin{array}{l}\text { f) novas obrigações e atribuiç̃̃es criadas pelo governo federal, } \\
\text { sem a devida contrapartida financeira }\end{array}$ & $15 \%$ & $64 \%$ \\
\hline $\begin{array}{l}\text { g) desinteresse dos gestores, por não representar uma ação } \\
\text { política que some votos }\end{array}$ & $43 \%$ & $64 \%$ \\
\hline
\end{tabular}

Fonte: Elaborada pelos autores, 2017.

Ainda, observou-se que, no grupo 3, os efeitos da crise foram mais relevantes, pois esses municípios são os mais dependentes das transferências, como FPM, e que as novas obrigações e atribuições criadas pelo Governo Federal, sem a devida contrapartida financeira, estão colocando-os frente a outras 
dificuldades, reduzindo a capacidade de investimento e principalmente de controle das despesas com folha de pagamento, a qual é regrada pela LRF.

Em questionamento final, os inspetores tributários e/ou fiscais foram interrogados sobre o nível de implementação de ações focadas no crescimento da arrecadação própria, considerando três níveis: inicial, intermediário e avançado, de acordo com os critérios propostos. O grupo 3 apresentou mais de $60 \%$ dos municípios em estágio inicial de implementação de ações focadas na ampliação da arrecadação própria. Resultado consistente com o exposto pelos entrevistados, que ressaltaram as inúmeras as dificuldades enfrentadas pelo setor nesses municípios, as quais vão desde a carência de profissionais capacitados até a falta de políticas públicas.

Resultado que encontra amparo em Resende (2002) quando discute que, entre os principais problemas da gestão pública está a falta de profissionalismo na condução de ações públicas, implicando em avaliações incorretas das políticas e programas públicos e, conforme complementa Dye (2005), limitações que poderão perpetuar os problemas e a ineficiências das ações públicas.

Por outro lado, os municípios do grupo 2 apresentaram desenvolvimento mais avançados das ações, o que se deve entre outros fatores ao maior número de profissionais atuando e implementando ações para ampliar a arrecadação e combater a sonegação, caso da nota fiscal eletrônica. Nesse grupo, destaca-se Vera Cruz que enquadrou-se no nível avançado, apresentando além da estrutura organizacional diferenciada, dotação específica para o setor tributário, fiscais atuando in loco, como também realizou o recadastramento imobiliário no período de análise e desenvolve diversas ações do PIT, inclusive auxiliando alguns municípios na implementação da Educação Fiscal.

Desenvolvimento que alinha-se ao discutido por Anselmo (2013) quando evidencia que a meta de arrecadação de tributos próprios deve ser baseada por um conjunto de variáveis locais contidas em um sistema de informação municipal, composto por dados detalhados de imóveis, de empresas, dos prestadores de serviços e dos munícipes.

\section{Conclusões}

A partir da proposta de analisar a estrutura orçamentária dos municípios do COREDE do Vale do Rio Pardo, no período de 2009 a 2016, discutindo as alternativas à arrecadação própria, constatou-se que, para os municípios mais dependentes de transferências governamentais, a agricultura constitui-se como base da atividade econômica, levando a um fraco desempenho da arrecadação de seus tributos em função da natureza dessa tributação. A partir disso, características específicas dos municípios foram observadas quanto a análise da estrutura arrecadatória.

Para os municípios do grupo 1, a média da arrecadação própria foi de 11,68\%, o dobro do grupo 2, que teve média de 5,35\% e quatro vezes maior que a dos municípios do grupo 3, para os quais a participação média foi de apenas 2,51\%. 0 tributo próprio mais representativo para ambos os grupos foi o ISS, com representatividade média superior a $40 \%$ do total das receitas próprias, porém os dois municípios mais populosos apresentam variabilidade bem menor entre o ISS e o IPTU. 
Paralelamente a esse cenário, evidenciou-se as dificuldades na expansão das receitas próprias que, além da carência de profissionais técnicos e capacitados, unânime para os grupos 2 e 3, apresentou falta de políticas públicas, novas obrigações e atribuições criadas pelo Governo Federal sem a devida contrapartida financeira; também destaca-se o desinteresse dos gestores, por não representar uma ação política que some votos, condizente com a cultura do clientelismo e patrimonialismo.

No que tange as propostas de alternativas à expansão da arrecadação própria, os municípios dos grupos 2 e 3 não apresentam estrutura organizacional distinta com dotação específica às áreas tributária e fazendária, conforme preceitos legais. Se por um lado, para municípios do grupo 3 é inviável a manutenção de servidor diretamente à fiscalização, dada a insuficiência de demanda. Por outro, para os do grupo 2 implementaram ações específicas para o controle e fiscalização da arrecadação do ISS, com resultados positivos em termos de arrecadação. Resultado que associa-se ao nível de implementação de ações, indicando que, quanto maior o município, maior a estrutura organizacional, menor as pressões políticas no setor e mais desenvolvidos os setores de tributação e arrecadação.

Sintetizando, os resultados permitiram ratificar que a arrecadação de tributos próprios deve ser priorizada e formulada a partir de política adotada pelo município. Além disso, evidenciou-se que os municípios dos grupos 2 e 3 estão na fase inicial de implementação de ações (em torno de 60\%), porém estão buscando alavancar a arrecadação própria, mesmo que ainda, caso da maioria, não tenha se adequado as exigências normatizadas pelo TCE/RS.

Por fim, o estudo é amplo e não se exaure, pois abre possibilidades de novas investigações que analisam alternativas às expansões da arrecadação própria municipal, principalmente em períodos de crise financeira, fiscal e institucional. Também, quanto aos gestores, faz-se importante atualizar o marco legal que regulamenta os diversos fluxos de recursos que compõem o orçamento em nível local, dos recursos próprios e da discussão da redistribuição de recursos orçamentários entre as esferas de governo.

A despeito da relevância dessas evidências, certas situações implicaram em limitações às análises. Cita-se a dificuldade de realização das entrevistas, dado que nem todos os servidores sentem-se livres para explanar suas opiniões sobre o desenvolvimento do fluxo de seu trabalho, embora muitos desempenham o trabalho com isonomia política, e a precariedade das informações de alguns sites municipais de transparência como também a reduzida literatura sobre finanças municipais. Estes aspectos engendram a necessidade do aprofundamento das análises sobre as finanças dos municípios.

\section{REFERÊNCIAS}

ABRÚCIO, F. L. A coordenação federativa no Brasil: a experiência do período FHC e os desafios do governo Lula. Revista de Sociologia Política, v. 24, p. 41-67, jun. 2005. 
ANSELMO, J. L. Tributo municipal. Série Educação Fiscal para a Cidadania. Fundação Prefeito Faria Lima. Centro de Estudos e Pesquisas de Administração Municipal. São Paulo. 2013.

BAIAO, A. L. O papel das transferências intergovernamentais na equalização fiscal dos municípios brasileiros. Dissertação (Mestrado). Escola Brasileira de Administração Pública e de Empresas, Centro Acadêmico e Pesquisa. Rio de Janeiro: 2013.

BRASIL. Finanças: procedimento para otimizar a arrecadação municipal. Confederação Nacional de Municípios (CNM). Brasília: CNM, 2012.

BRITO, H. S.; DIAS, R. R. O Comportamento da Receita Pública Municipal: Um Estudo de Caso no Município de Parnaíba - PI. Revista de Gestão e Contabilidade da UFPI, [S.I.], v. 3, n. 1, p. p.130-146, dez. 2015.

BORGES, E. F. Educação fiscal e eficiência pública: um estudo das suas relações a partir da gestão de recursos pela administração municipal. 2012.

CAMPOS, M. G.; JUNIOR, O. D. A estratégia de municipalização do imposto territorial rural (ITR): oportunidade de promover o desenvolvimento rural sustentável ou penalização aos municípios brasileiros?. In: IV JORNACITEC. 2015.

CASTAGNA, G. et al. Georreferenciamento de atividades econômicas municipais: metodologia do desenvolvimento e aplicações. 2005. Repositório UFSM.

. Finanças: procedimento para otimizar a arrecadação municipal. Confederação Nacional de Municípios (CNM). Brasília: CNM, 2012.

. Constituição Federal (1988). Constituição da República Federativa do Brasil. Brasília: Senado Federal, 2013.

. Lei da responsabilidade fiscal. Lei Complementar $n^{\circ} 101$, de 4 de maio de 2000. Disponível em <http://presrepublica.jusbrasil.com.br/legislacao/102628/lei-deresponsabilidade-fiscal-lei-complementar-101-00>. Acesso em: 01. set. 2015.

. Lei 4.320 (1964). Institui normas Gerais de direito financeiro para elaboração e controle dos orçamentos e balanços da União, Estados, Municípios e do Distrito Federal. Publicada pelo Congresso Nacional em 17 de março de 1964. Disponível em: <http//www.pl analto.gov.br/ccivil_03/leis/L4320, htm>. Acesso em: 01 set. 2015 .

CONFEDERAÇÃO NACIONAL DE MUNICÍPIOS - CNM. Gestão Municipal: Projetos em Ação - Boas Práticas compartilhadas para as finanças municipais- 2016. Disponível em <http ://www.cnm.org.br/portal/dmdocuments/Gest\%C3\%A30\%20 Municipal .\%20Projetos20em\% 20\%C3\%A7\%C3\%A30\%20(2016).pdf> Acesso em 15 de fev. 2017. 
. Gestão Municipal: FPM de 2016 foi salvo com recursos da repatriação.

Disponível em <http://cnm.org.br/cms/biblioteca_antiga/FPM\%20de\%202016\%20 foi\%20 salvo \%2opelos\%2orecursos\%20da\%2orepatria\%C3\%A7\%C3\%A30\%20 (fevereiro\% 20de \%202017).pdf> Acesso em 01 mar de 2017.

. Gestão Municipal: Projetos em Ação - Boas práticas compartilhadas para as finanças municipais. Brasília: CNM, 2015.

. Estudos Técnicos: Crise dos municípios - a falta de recursos. Volume 7. Janeiro, 2015.

. http://vivaseumunicipio.cnm.org.br/assets/img/download/A-Real-Situacaodos-Municipios-Brasileiros.pdf CONSELHO REGIONAL DE DESENVOLVIMENTO DA REGIÃO SUL - COREDE SUL. Disponível em<http://www.coredesul.org.br/Pagina/9/ O-QUE-SAO-E-COMO-FUNCIONA M-OS-COREDES-\%96RS>. Acessado em 25 mai. 2016.

CONSULTORIA, AEQUUS. Multicidades - Finanças dos Municípios do Brasil: 2017. Frente Nacional de Prefeitos, v. 12, p. 180, 2017. Disponível em: <http://multimidia.fnp.org. br/biblioteca/publicacoes/item/476-anuario-multicidades-2017>Acesso em 30 jan. 2017.

CRUZ, F. (Coord.). Comentários à Lei nº 4·320.5.ed. São Paulo: Atlas, 2008.

DE SOUSA BRITO, H.; DIAS, R. R. O comportamento da Receita Pública Municipal: um estudo de caso no Município de Parnaíba-PI. Revista de Gestão e Contabilidade da UFPI, v. 3, n. 1, p. p. 130-146, 2015.

DYE, T. R. Understanding public policy. 11 ed. Upper Saddle River, New Jersey: Prantice-Hall, 2005.

EIDT, S. L.; DE LIMA, J. F. Descentralização tributária no Brasil: um pacto federativo para os Municípios, Estados e a União Federal. Redes, v. 12, n. 2, p. 257-270, 2008.

FEDERAÇÃO DAS ASSOCIAÇÕES DE MUNICÍPIOS DO RIO GRANDE DO SUL FAMURS. Disponível em: <http://www.famurs.com.br/index.php?option=com content \&view=Article\&id=806:municipios-tem-problemas-para-fiscalizarimpostos\&catid=14: receitas-municipais\&Itemid=233>. Acessado em 25. mai. 2015.

. Disponível em http://www.famurs.com.br/arq_upload/20170117154111_ reestimativas \%20para\%202016\%20sem\%2orepatriacao.pdf> Acesso em 22. Jan. 2017.

FEE - Fundação de Economia e Estatística Siegfried Emanuel Heuser. Disponível em:<http:// www.fee.rs.gov.br/perfil-socioeconomico/coredes/detalhe/?corede= Vale+ do+ Rio + Pardo $>$. Acessado em 25. mai. 2016. 
FINANÇAS PÚBLICAS DO BRASIL - ÍNDICES FIRJAM DE GESTÃO FISCAL. Disponível em:< http://www.firjan.com.br/ifgf>. Acessado em 25. jan. 2017.

FLORES, P. C.; RICHATO, A. F. O Plano Plurianual nos Municípios. 1.ed. Porto Alegre: IGAM, 2017.

GIACOMONI, J. Orçamento Público. 8.ed. São Paulo: Atlas, 1998.

IBGE - Instituto Brasileiro de Geografia e Estatísticas. Estatísticas. Disponível em http://www.ibge. gov. br/home/>Acessado em 25 mai. 2016.

JARDIM, E. M. F. Manual do direito financeiro e tributário. 12.ed. São Paulo: Saraiva. 2011.

JÚNIOR, A. M. N. et al. A efetividade dos programas de educação fiscal e da nota fiscal paulista na construção da cidadania e no crescimento da arrecadação tributária. Revista Gestão e Desenvolvimento, v. 16, n. 3, p. 106-133, 2019.

KLEBA, M. E.; ZAMPIROM, K.; COMERLATTO, D. Processo decisório e impacto na gestão de políticas públicas: desafios de um Conselho Municipal de Saúde. Saúde e Sociedade, v. 24, p. 556-567, 2015.

KOHAMA, H. Contabilidade Pública: Teoria e Prática. 12.ed. São Paulo: Atlas, 2012

YIN, R. K. Estudo de caso: planejamento e métodos. 3.ed. Porto Alegre: Bookman, 2005.

2015.

. Estudo de caso: planejamento e métodos. 5.ed. Porto Alegre, RS: Bookman,

LAKATOS, M. A.; MARCONI, E. M. Fundamentos de metodologia científica. 5.ed. São Paulo: Atlas, 2003.

Fundamentos de metodologia científica. 7.ed. São Paulo: Atlas, 2010.

LOPES, A. S. 1927-2010. Teoria da contabilidade. 5.ed. São Paulo, SP: Atlas, 2010.

MARTINS FILHO, L. N. Eficiência na gestão fiscal: um estudo sobre a arrecadação de receitas próprias do município de alagoinhas/BA entre 2001/2006. 2007.

PRADO, S. Introdução conceitual e visão geral do sistema. In: PRADO, Sérgio (Org.). Transferências Intergovernamentais a Federação Brasileira: avaliação e alternativas de reforma. Rio de Janeiro: Fórum Fiscal dos Estados Brasileiros, Caderno n. 6, v. 2, 2007.

PETRY, H. Á.; SILVEIRA, R. L. L. Plano estratégico de desenvolvimento regional do Vale do Rio Pardo (2015-2030). Santa Cruz do Sul: EDUNISC, 2017. 
RIO GRANDE DO SUL. Tribunal de Contas do Estado. Orientação do Tribunal de Contas para gestores. Porto Alegre: TCE/RS. 2014.

. Diagnóstico sobre a estrutura e a logística da administração tributária municipal. Disponível em: < http://www1.tce.rs.gov. br/Portal/page/portal/tcers/ publicacoes/estudos/estudos_pesquisas/adm_trib_municipal/Diagnostico_ admin_tribut_\%2omunicipal.pdf >. Acessado em 25. mai. 2016.

. Cartilha Racionalização da Cobrança da Dívida Ativa Municipal. Disponível em: <http://www.tjrs.jus.br/site/ imprensa/destaques/doc/Cartilha_racionalizacao_ dez_2014.pdf> Acesso em 20 de fev. de 2017.

RESENDE, F. C. O dilema do controle e a falha sequencial nas reformas gerenciais. Revista do Serviço Público, Brasília, n.3, p.50-74, 2002.

REZENDE, F. Os Desafios do Federalismo Fiscal. In: REZENDE, F. (Org.). Desafios do Federalismo Fiscal. Rio de Janeiro: FGV Editora, 2006.

ROCHA, V. S. F. Gestão Tributária Municipal: apostila. Porto Alegre: DPM Educação, Set. 2017.

SANTOS, K. G. B.; SANTOS, C. E. R. Dependência Municipal das Transferências do Fundo de Participação dos Municípios: uma análise para os municípios do Sul da Bahia entre 2008 e 2012. Anais da IV Semana do Economista, v. 7, 2008.

SANTOS G. A. G. et al.; Potencial de arrecadação Municipal e o PMAT. Revista do BNDES, Rio de Janeiro, v. 14, n. 29, p. 399-434, jun. 2008.

SCUR, R. B.; PLATT NETO, O. A. Diagnóstico da dependência dos repasses federais e estaduais no município de Canela-RS. Revista Catarinense da Ciência Contábil, v.10, n.29, p. 53-68, 2011.

SILVA, L. M. Contabilidade Governamental. 3.ed. São Paulo: Editora Atlas, 1996.

SOUZA, C. Governos locais e gestão de políticas sociais universais. São Paulo em perspectiva, v. 18, n. 2, p. 27-41, 2004.

WAKULICZ, G. J.; SERPA, I. M. Receitas Próprias: Um Estudo do Município de Gramado dos Loureiros-RS. II Encontro de Economia Catarinense da APEC, p. 27$100,2008$.

TEIXEIRA, E. C. O papel das políticas públicas no desenvolvimento local e na transformação da realidade. Salvador: AATR, 2002.

TEIXEIRA, J. R. B. $O$ atual desequilíbrio no sistema de repartição de receitas tributárias. Estudos da Consultoria Legislativa da Câmara dos Deputados, 2005. 
Reisoli Bender Filho. Doutor em Economia Aplicada. Universidade Federal de Santa Maria.Professor. reisolibender@yahoo.com.br

Mariângela Ravanello. Mestre Gestão de Organizações Públicas. Universidade Federal de Santa Maria. Estudante.mary-r131@hotmail.com.

\section{Submetido em: 08/08/208}

Aprovado em: 30/07/2020

Como citar: BENDER, Reisoli Filho; RAVANELLO, Mariângela. Expansão das receitas próprias: análise das alternativas dos municípios da Região do Vale do Rio Pardo RS. Redes (St. Cruz Sul, Online), Santa Cruz do Sul, v. 25, p. 1812-1839, nov. 2020. ISSN 19826745. doi:https://doi.org/10.17058/redes.v25i4.12443.

\section{CONTRIBUIÇÃO DE CADA AUTOR}

a. Fundamentação teórico-conceitual e problematização: Mariângela Ravanello e Reisoli Bender Filho.

b. Pesquisa de dados e análise estatística: Mariângela Ravanello e Reisoli Bender Filho

c. Elaboração de figuras e tabelas: Mariângela Ravanello

d. Elaboração e redação do texto: Mariângela Ravanello e Reisoli Bender Filho.

e. Seleção das referências bibliográficas: Mariângela Ravanello e Reisoli Bender Filho

Fontes de financiamento: não se aplica. 